\title{
A commentary on the paper: Facial trauma in the Trojan War
}

\author{
Dimosthenis Igoumenakis ${ }^{1}$
}

Received: 3 October 2016/Accepted: 11 October 2016/Published online: 19 October 2016

(C) Springer-Verlag Berlin Heidelberg 2016

Dear Editor,

I studied the paper "Facial trauma in the Trojan War" by Ralli et al. [1]. The injuries involving the head and neck region reported in the ancient Greek literature have already been recorded and published $[2,3]$. Nevertheless, this is the first work to record and demonstrate the injuries confined to the face, which are described in the Homer's Iliad. This fact renders the paper unique and therefore the authors are praiseworthy.

The details about facial injuries mentioned in the Iliad are summarized in Table 1, according to which the cases $\mathrm{Nr} 8$ and $\mathrm{Nr} 12$ involve decapitation of the defender by the attacker resulting in death. However, after studying the respective verses in the Homer's manuscript, I identified that in these two cases, none of the decapitations was the actual cause of death $[4,5]$. On the contrary, both were undertaken postmortem, as the attacker intended to use the head of the defender's corpse as a trophy.
I would recommend this issue be clarified by the authors.

\section{References}

1. Ralli I, Stathopoulos P, Mourouzis K, Piagkou M, Rallis G (2015) Facial trauma in the Trojan War. Oral Maxillofac Surg 19:191-194

2. Konsolaki E, Astyrakaki E, Stefanakis G, Agouridakis P, Askitopoulou H (2010) Cranial trauma in ancient Greece: from Homer to classical authors. J Craniomaxillofac Surg 38:549-553

3. Sapounakis C, Rallis G, Mourouzis C, Konsolaki E, Tesseromatis C (2007) Injuries to the head and neck in Homer's Iliad. Br J Oral Maxillofac Surg 45:112-115

4. Komninou-Kakridis O (1954) Homer, the iliad (translation in modern Greek) I. Zaharopoulos, Athens

5. Murray AT (1924) Homer. The Iliad with an English translation. Heinemann, London

Dimosthenis Igoumenakis

digoumen@gmail.com

1 Department of Oral and Maxillofacial Surgery, General Hospital of Heraklion "Venizeleio", Knossos Avenue, 17409 Heraklion, Greece 